\title{
Therapeutic Potential of Limbal Mesenchymal Stem Cell Secretome for Repair Ocular Surface in Experimental of Dry Eye Disease

\author{
Ni Made Inten Lestari ${ }^{1}$, Evelyn Komaratih ${ }^{1}$, Fedik A. Rantam ${ }^{2}$, Yuyun \\ Rindiastuti ${ }^{1}$, Cita R.S Prakoeswa ${ }^{3}$
}

\author{
official email address: intenlestari@gmail.com \\ ${ }^{1}$ Department of Ophthalmology, Faculty of Medicine Universitas Airlangga/ Dr. Soetomo General Academic Hospital, J1. Mayjen. Prof. \\ Dr. Moestopo 4-7, Surabaya,60286, Indonesia \\ ${ }^{2}$ Stem Cell Research and Development Center, Universitas Airlangga, Tropical Disease Center Building, $2^{\text {nd }}$ Floor, Kampus C \\ Mulyorejo, Surabaya, Indonesia \\ ${ }^{3}$ Department of Dermatovenerology, Faculty of Medicine Universitas Airlangga/ Dr. Soetomo General Academic Hospital, Jl. Mayjen. \\ Prof. Dr. Moestopo 4-7, Surabaya, Indonesia
}

\begin{abstract}
Background: The objective of this study to explain relationship limbal mesenchymal stem cell secretome (L-MSC) for repair ocular surface in experimental model of dry eye disease (DED)

Methods: The research design used experimental study. Pre and post experimental study composed of topical instillation of limbal mesenchymal stem cell secretome group, balance salt solution (BSS) group, and normal control group.

Result: Topical instillation of limbal mesenchymal stem secretome improved regeneration of corneal epithelial cell ( $\mathrm{p}$ $>0.05)$ and promoted goblet cell restoration $(\mathrm{p}=0.016)$

Conclusion: In conclusion, topical instillation of limbal mesenchymal stem secretome has potential regenerist therapy to preserve ocular surface in experimental DED model
\end{abstract}

Keyword: limbal mesenchymal stem cell; secretome; dry eye disease

\section{Introduction}

Dry eye disease is a chronic ocular condition and significantly impacts visual function with multifactorial origin. In recent years, the epidemiology of DED is increased. The incidence and prevalence in Asia is higher than in Europe and America suggesting racial factor are involved in dry eye etiology [1]. In Indonesia, the majority of DED is $37,6 \%$ by $40-49$ year age group and 1,4 times higher for men than women [2].

Defect on tear film components due to oxidative stress lead ocular surface epithelial exposed triggered inflammatory process. Recently, the management of DED is supportive. Application of artificial tears, topical anti-inflammatory, and immunosuppressant is standard therapy for DED. However, the results obtained less optimal. Mesenchymal stem cell is characterized non-hematopoietic, multipotent progenitor cell, and morphology like fibroblast [3]. In particular, Limbal MSC have been shown to encourage the regeneration of corneal epithelial cells derived from limbal tissue biopsies. However, availability and cultivation of healthy donor remain challenges such as limited sources. Secretome originated from mesenchymal stem cell that contain wide variety of bioactive substances, soluble factor, growth factor, and anti-inflammatory[3],[4]. In the future, secretome has a potency as a candidate acellular regenerative therapy that promises in management ocular surface disease including DED. 


\section{Subjects and Methods}

\subsection{Animal model}

A total of 30 New Zealand white rabbit were randomly divided into three groups. Twenty rabbits inducted with intraperitoneal injection of xylazine-ketamine. The operation were performed under sterile condition. Resection of the partial inferior lacrimal gland combined with interglandular injection of $300 \mu \mathrm{g}$ Concanavalin A (Con A; Sigma-Aldrich) diluted in 20 ul PBS using a Hamilton syringe with a 33 gauge needle were performed to create animal model. Five days after induction, the schirmer tear test and corneal fluorescein test was examined. The schirmer tear test less than $4 \mathrm{~mm}$ was included in this study [5].

\subsection{Secretome limbal mesnchymal stem cell}

The cell was obtained from the stem cell laboratory, Universitas Airlangga. To obtained secretome, amount of $5 \times 10^{3}$ cell/well of L-MSC was treated treated for 24 hours using media composed of $\alpha$-MEM, $1 \%$ amphotericin B, $1 \%$ NEAA, $1 \%$ penicillin-streptomycin, and $2 \%$ FBS). The secretome was collected and filtered using $0.45 \mathrm{um}$ millipore, the osmolarity and acidity were adjusted for $270-300 \mathrm{mOsm} / \mathrm{L}$ and 7.2-7.5, respectively. The secretome was packaged into single dose application in sterile eppendorf tube and stored at $20^{\circ} \mathrm{C}$ until further application

\subsection{Corneal fluorescein dye staining}

Using sodium fluorescein test strips instill into the inferior lateral conjunctival sac. The corneal surface was observed in the portable slit lamp, cobalt blue light, and zoom 16 times. The picture was taken using camera (Canon, A2500, 16 Megapixel) and analyzed using image J (v1.48) in 3 times by independent observer

\subsection{Goblet cell density}

Exenteration procedure was performed and stored in formalin. The histopathology section sliced in $4 \mu \mathrm{m}$ and subjected to hematoxylin eosin staining. Using Nikon H600L microscope under 400x magnification goblet cell density was observed. The characteristic of goblet cell are rounded and plump. Goblet cell dencity was counted using using cell count Nikkon Image symtem. The result was validated by an anatomic pathologist.

\subsection{Statistical analysis}

The data was processed using SPSS version 21.0 where $\mathrm{P}<0.05$ was considered to be statistically significant. Statistical measures presented in descriptive table (e.g mean and standard deviation). Statistical analysis between group was analyzed with Kruskal Wallis variance analysis and independence T-test

\section{Results}

\subsection{Limbal mesenchymal stem cell secretome promote regeneration of corneal epithelial cell}

L-MSC secretome promote regeneration of ocular surface on day 7 compared to BSS control group (Figure 1). The fluorescein dye staining area on L-MSC group markedly decreased $\left(2.88 \times 10^{5} \pm 7.98 \times 10^{4}\right.$ pixel $)$ compared to BSS control group $\left(1.08 \times 10^{6} \pm 1.05 \times 10^{4}\right.$ pixel $)$ (Table 1).

Tabe 1. The effect instillation L-MSC to repair ocular surface

\begin{tabular}{lcccc}
\hline Treatment Group & $\mathbf{n}$ & $\begin{array}{c}\text { Fluorescein dye } \\
\text { staining area Day-0 } \\
\text { (Pixel) }\end{array}$ & $\begin{array}{c}\text { Fluorescein dye } \\
\text { staining area Day-7 } \\
\text { (Pixel) }\end{array}$ & p \\
\hline L-MSC secretome & 10 & $8.15 \times 10^{6} \pm 3.67 \times 10^{4}$ & $2.88 \times 10^{6} \pm 8.51 \times 10^{4}$ & $<0.001^{*}$ \\
BSS & 10 & $7.98 \times 10^{5} \pm 2.09 \times 10^{4}$ & $1.08 \times 10^{5} \pm 1.05 \times 10^{4}$ & $<0.001^{*}$ \\
\hline $\mathrm{p}$ & & 0.377 & $<0.001$ & \\
\hline
\end{tabular}



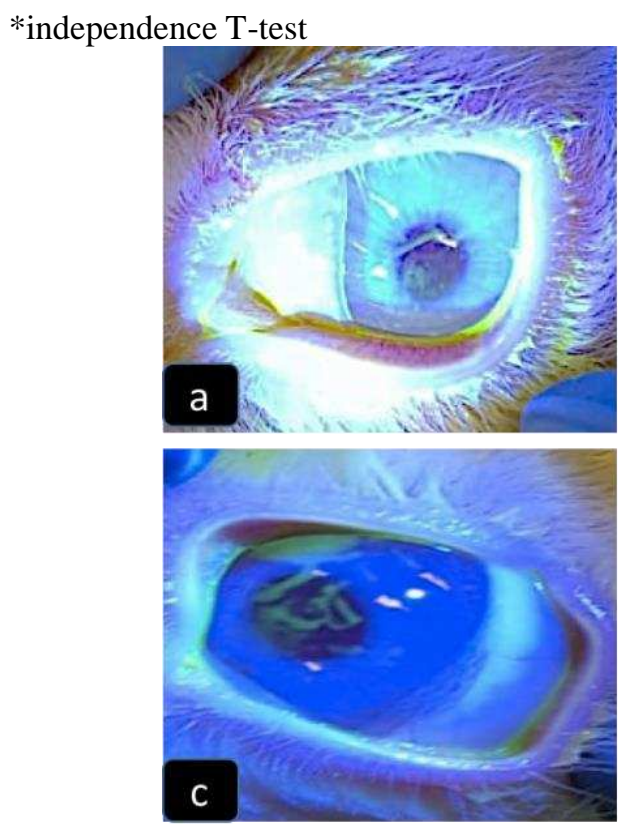
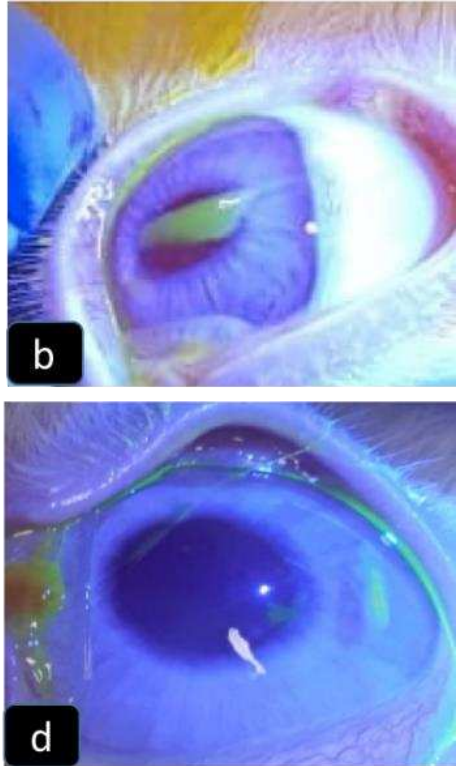

Figure 1: Topical instillation of L-MSC secretome promoted corneal epithelial regeneration. (A). Fluorescein dye staining in BSS group day 0; (B). L-MSC secretome group day 0; (C) BSS group day 7; D L-MSC secretome group day 7. Green staining: Fluorescein staining in corneal epithelial defect.

\subsection{Instillation of Limbal MSC secretome repaired of goblet cell}

The conjunctival goblet cells has important role to secreting mucin. The musin has a role involving in formation tear film. In this study, goblet cell density count was significantly higher in the eyes with topical instillation of L-MSC secretome $(2.54 \pm 0.69$ cells/ visual field, $\mathrm{p}=0.016)$ compared to the BSS control group (Table 2, Figure 2).

Table 2. The effect instillation L-MSC to restored of goblet cell in conjunctiva

\begin{tabular}{cccc}
\hline Group & $\mathbf{n}$ & $\begin{array}{c}\text { Goblet cell density } \\
\text { (cell/visual field) }\end{array}$ & p \\
\hline L-MSC & 10 & $2.54 \pm 0.69$ & \\
$\begin{array}{c}\text { Secretome } \\
\text { BSS }\end{array}$ & 10 & $0.98 \pm 0.24$ & $<0.016^{*}$ \\
Normal control & 10 & $13.12 \pm 2.50$ & \\
\hline
\end{tabular}

*(One Way ANOVA, Tukey post-hoc test) 


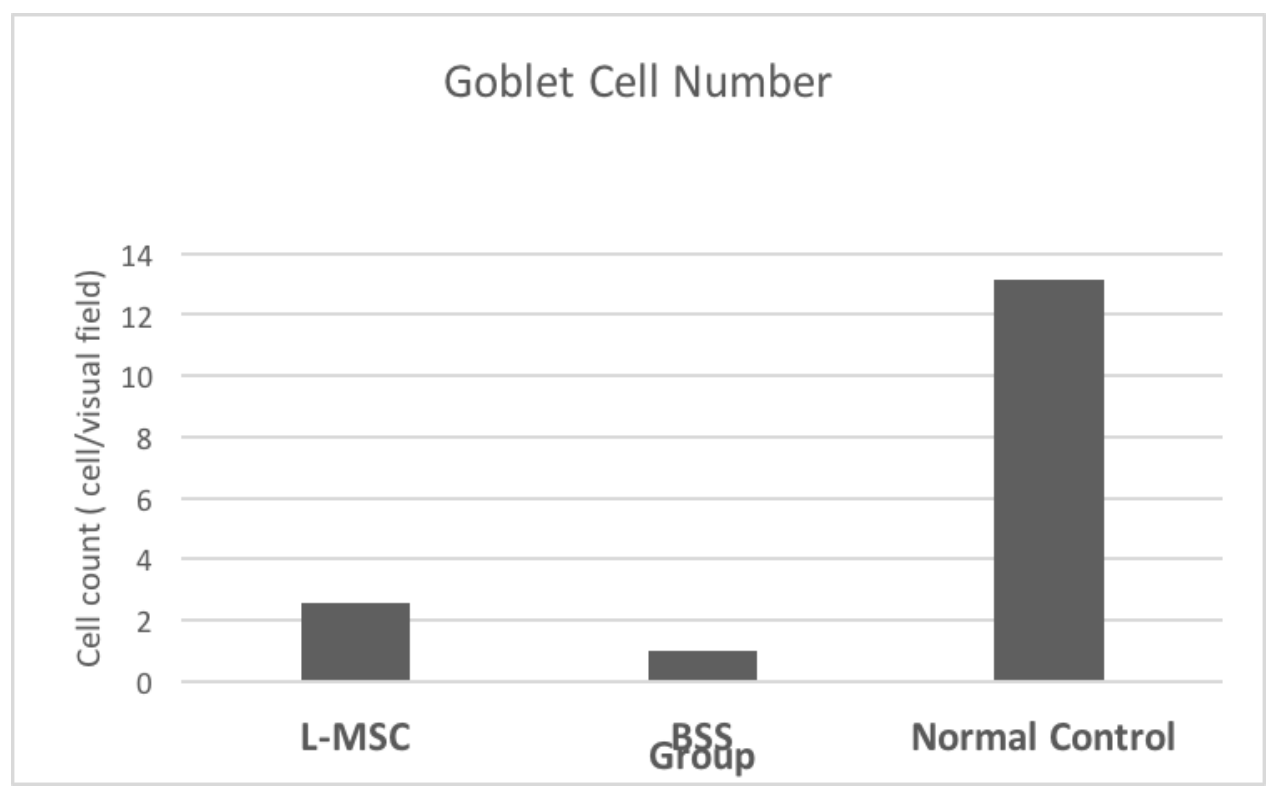

Figure 2. The graph showed goblet cell density among group

\section{Discussion}

Dry eye disease is a chronic ocular condition and significantly impacts visual function with multifactorial origin [6],[7]. It is characterized by tear instability and inflammation on the ocular surface. The growth factor such as epidermal growth factor (EGF) and keratinocyte growth factor (KGF) has important role to repair and regenerate ocular surface[8],[9]. Stem cell secretome has various growth factor might have beneficial effect on ocular surface regeneration. In severe dry eye disease, there is epithelial damage on corneal surface.

In this study, topical instillation of L-MSC secretome successfully promote corneal epithelial regeneration. In line with this study, other study demonstrated that secretome derived from limbal fibroblast had therapeutic effect such as promote limbal stem cell proliferation and differentiate into corneal epithelial in mouse model of limbal stem cell deficiency [10]. Some studies showed the regeneration of corneal wound healing after instillation MSC secretome by cell to cell interaction and surrounding tissue mechanism such as proliferation, differentiation, communication, and migration [11],[12].

The primary mechanism of dry eye disease associated with tear film abnormalities. The tear film is composed of three main layers. The outermost layer is formed predominantly of lipid, which function is to prevent water evaporation and reduce the tension of the ocular surface. The middle is an aqueous layer and plays a role in protecting against pathogens and particle and hydration ocular surface [13],[14]. Its contain insoluble and soluble component such as proteins, electrolytes, peptides, and small molecules. The innermost layer is a mucin layer that resides directly at the surface of the cornea. Mucin originated from the goblet cell. Goblet 
cell loss in the conjunctival epithelium decreased concentration of mucin in tear film and correlate with DED symptom.

In this study, instillation of limbal MSC secretome preserved of goblet cell. In line with this study revealed there were increased number of goblet cell in conjunctiva epithelium after topical instillation of bone marrow mesenchymal stem cell in experimental dry eye model[15]. Another study, instillation of human uterine cervical stemcell secretome in rat model of dry eye disease revealed increased corneal epithelial wound healing process[16]. There are limited report of studies using topical L-MSC secretome in ocular surface particularly in DED. The secretome is composed growth factor, soluble factor, microvesicles that have role in wound healing process and promising as regenerative study.

Limitation on this study, the exact content of the secretome has yet determined, further studies are mandatory to analyze composition of the L-MSC secretome.

\section{Conclusion}

In conclusion, topical instillation of limbal mesenchymal stem secretome has potential effect regenerist therapy to preserve ocular surface in experimental DED model.

\section{Acknowledgement}

None

\section{Financial Support}

The funding is supported by Dana Hibah Mandat Project, Universitas Airlangga Surabaya, Indonesia.

\section{Conflict of Interest}

Nil.

\section{Ethical Satandard}

Ethical approval was obtained from Institutional Ethical Committee of Faculty of Veterinary medicine, Universitas Airlangga (No: 2.KE.053.06.2020). All Prosecures performed with ethical standards.

\section{References}

1. Tsubota K, Pflugfeder SC, Liu Z, Baudouin C, Kim HM, Messmer EM et al. Defining Dry eye from a clinical perpective. Int J Mol Sci . 2020;21(23):9271

2. Lee AJ, Lee J, Saw SM, Gazzard G, KOh D, Widjaja D, Tan DT. Prevalence and risk factor associated with dry eye symptoms: a population-based study in Indonesia. Br J Ophthalmol.2002.86(12):1347-51

3. Villatoro AJ, Alcoholado C, Astorga MCM, Rico G, Fernadez V, Becerra J. Characterization of the secretory profile and exosomes of limbal stem cells in the canine species. Plos One. 2020;15(12).

4. Meiliana A, Dewi NM, Wijaya A. Mesenchymal stem cell secretome : cell-free therapeutic strategy in regenerative medicine. Indones Biomed J. 2019;11(2):113-24. 
5. Bittencourt MK, Barros MA, Martins JF, Vasconcellos JP, Morais BP, Pompeia C et al,. Allogenic mesenchymal stem cell transplantation in dog with keratoconjunctivitis sicca. Cell Med. 2016;8(3):63-77

6. Akpek EK, Bunya VY, Saldanha IJ. Sjogren syndrome: more than just dry eye. Cornea. 2019.38(5):658-661

7. Cwiklik L. Tear film lipid layer: A molecular-level view. Biochimic Biophys Acta. 2016.1858(10):2421-30.

8. Chahadva P, Goldhardt R, Galor A,. Meibomian gland disease: the role of gland dysfunction in dry eye disease. Ophthalmology.2017.124(11):20-26.

9. Phadatare Sp, Momin M, Nighojar P, Askarkar S, Sing KK,. A comprehensive review on dry eye disease: diagnosis, medical management, recent development, and future challenges. Advance in Pharmaceutics. 2015.article ID 704946.

10. Amirjamshidi H, Milani BY, Sagha HM, Movahedan A, Shafiq MA, Lavker RM, Yue BYT, Djalilian AR. Limbal fibroblast conditioned media: A non-invasive treatment for limbal stem cell deficiency. Mol Vis. 2011;8(17):658-66.

11. Yazdanpanah G, Haq Z, Kang K, Jabbehdari S, Rosenblatt M, Djalilian AR. Strategies for reconstructing the limbal stem cell niche. Ocular Surface. 2019;17(2): 230-40

12. Shibata S, Hayashi R, Okubo T, Kudo Y, Baba K, Honma Y, Nishida K. The secretome of adiposederived mesenchymal stem cells attenuates epithelial-mesenchymal transition in human corneal epithelium. Regen Ther. 2019;11:114-122.

13. Dietrich J, Roth M, Konig S, Geerling G, Mertsch S, Schrader S. Analysis of lacrimal gland derived mesenchymal stem cell secretome and its impact on epithelial cell survival. Stem Cell Research. $2019 ; 101477$.

14. Huang JF, Zhang Y, Kay DR, Pickering EH, McDowell MT,. Evaluation of tear protein markers in dry eye disease: repeatability of measurement and correlation with disease. Invest Ophthalmol Vis Sci. 2012: 53. 4556-4564.

15. Beyazyildiz E, Pinarli FA, Beyazyildiz O, Hekimoglu ER, Acar U, Demir MN. Efficacy of topical mesenchymal stem cell therapy in the treatment of experimental dry eye syndrome model. Stem Cells Int. 2014; 250230

16. Bermudez MA, Lago JS, Eiro N, Trevino M, Gonzalez F, Pimentel EY, Giraldez MJ et al. Corneal epithelial wound healing and bactericidal effect of conditioned medium from human uterine cervical stem cells. Inves Ophthalmol Vis Sci. 2015;56:983-992 